\title{
Utilization of healthcare facilities and associated factors among rural elderly in Kanyakumari District, Tamil Nadu
}

\author{
Ravindra Panicker P. ${ }^{1 *}$, Jerusha J D. P. ${ }^{2}$ \\ DOI: https://doi.org/10.17511/ijphr.2019.i1.01 \\ 1* Priya Ravindra Panicker, Assistant Professor, Department of Community Medicine, Sree Mookambika Institute of Medical Sciences, \\ Kanyakumari, Tamil Nadu, India. \\ 2 Prem Jerusha J D., Post Graduate Student, Department of Community Medicine, Sree Mookambika Institute of Medical Sciences, \\ Kanyakumari, Tamil Nadu, India.
}

\begin{abstract}
Background: Rapidly progressing population ageing in India translates into more chronic diseases and healthcare expenditure among the elderly. But inadequate geriatric centred services in rural areas may hinder the health seeking behaviour among rural elderly. Hence, this study was done to assess utilization of healthcare facilities by elderly in rural Kanyakumari and to identify factors associated with it. Methods: Elderly people above 60 years of age were selected from rural Kanyakumari by multistage sampling. 250 subjects for the cross-sectional study were finalised after excluding debilitated elderly. Data was collected by a pretested questionnaire after getting informed consent. Results: Mean age of the study group was 70.12 years. $60 \%$ of elderly were currently married while $70.8 \%$ elderly were unemployed. More than half of the elderly population (57.6\%) claimed to avoid healthcare facilities in times of need, citing cost of hospital care (27.6\%) and perceived triviality of illness as the most common reasons. More than $75 \%$ elderly used out of pocket expenditure to meet healthcare expenses. Most of them (96\%) did not have health insurance. Elderly people with education beyond primary school level and belonging to upper socioeconomic status had a statistically significant association with better healthcare utilization. Conclusion: Perception of disease as an age-related phenomenon has to be negated in order to improve healthcare utilization. Also, the importance of healthcare in improving functionality has to be conveyed to the community. Affordable and universal healthcare suited to geriatric needs have to be made available to the rural elderly population.
\end{abstract}

Keywords: Factors, Healthcare facilities, Rural elderly, Utilization

\section{Corresponding Author}

Priya Ravindra Panicker, Assistant Professor, Department of Community Medicine, Sree Mookambika Institute of Medical Sciences, Kanyakumari, Tamil Nadu, India. Email: priya.ravipanicker@gmail.com
How to Cite this Article

To Browse

Panicker PR, Jerusha J D P. Utilization of healthcare facilities and associated factors among rural elderly in Kanyakumari District, Tamil Nadu. Public Health Rev Int J Public Health Res. 2019;6(1):1-8. Available From

https://publichealth.medresearch.in/index.php/ijphr/ article/view/94

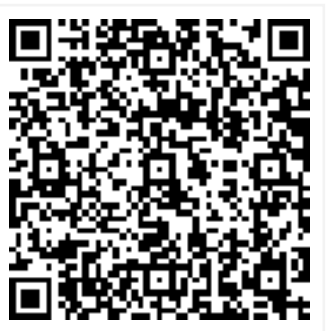

Manuscript Received 2019-01-18

Conflict of Interest No
Review Round 1 2019-01-28

Funding $\mathrm{Nil}$

$\begin{gathered}\text { Review Round } 2 \\ \text { 2019-02-05 }\end{gathered}$
Ethical Approval
Yes

Review Round 2 Yes
Review Round 3

Accepted 2019-02-09

Plagiarism $\mathbf{X}$-checker $7 \%$

Note

(C) 2019 by Priya Ravindra Panicker, Prem Jerusha J D. and Published by Siddharth Health Research and Social Welfare Society. This is an Open Access article licensed under a Creative Commons Attribution 4.0 International License https://creativecommons.org/licenses/by/4.0/ unported [CC BY 4.0]. 


\section{Introduction}

India is experiencing demographic transition at such alarming rates that it will soon be home to the world's second-largest population of elderly people above 60 years [1]. While the increased life expectancy is indeed a public health success, this ageing of the population poses a challenge to the healthcare systems, questioning their ability to deal with felt needs of the elderly population.

The ageing process in itself results in an increased susceptibility to diseases, co-morbidity, polypharmacy, loss of personal autonomy and high rates of disability [2]. In a developing country like India, this means the elderly are exposed to the double burden of communicable and noncommunicable diseases [3].

Chronic diseases and disability often lead to increased use of healthcare facilities and this in turn leads to increased healthcare expenditure. Moreover, latest innovations in medical technology and expensive medicines exert a greater influence on healthcare costs than population ageing itself [2].

The exorbitant costs of healthcare services often result in impoverishment of the family rather than improvement in the health of the elderly [4]. Daily functionality also follows a strong socio-economic gradient in India, revealing that the wealthy elderly have access to better healthcare facilities than the impoverished elderly [5]. WHO has also reported that catastrophic health expenditure is more among households with older people, rural households and in households headed by women [6].

Elderly people living in rural areas face a higher disadvantage of fewer geriatric care centred health services [5]. The morbidity profile and perception of health problems among rural elderly are very different from the urban elderly population. Lower socioeconomic status (SES) and lower financial stability may also hinder health seeking behaviour in rural elderly, unlike their urban counterparts. Such constraints are often magnified in rural elderly and the elderly women who are more likely to be unemployed or living alone.

The new era of Sustainable Development Goals aims to bring about Universal health coverage, 'leaving no one behind'. The goals of 'No poverty', 'Good Health', 'Gender Equality', and 'Reduced Inequalities' are aimed at people of all ages, especially the rural elderly who are more vulnerable to these
Inequalities [1].

In order to address the felt needs of the elderly and to improve healthcare service delivery in rural areas, disaggregated information regarding the utilisation of available services by the elderly and the potential factors that may influence utilisation patterns need to be obtained. Hence, this study was undertaken to assess the utilization of healthcare facilities by the elderly in the rural areas of Kanyakumari and to identify factors that are associated with healthcare utilization.

\section{Methods}

\section{Study design: Cross-sectional study}

Place of study: Thiruvattar block of Kanyakumari district, Tamil Nadu

Study duration: June 2015 to July 2016

Sample size calculation: Based on $65 \%$ elderly utilizing healthcare services as reported by Nipun Agarwal et al, p was taken as 65 with relative precision of $10 \%$ in the prevalence formula $4 \mathrm{pq} / \mathrm{L} 2$ to get a sample size of 215 [7]. This was then rounded to 250 study subjects.

Sampling methods: Multi-stage random sampling was done at three levels. By simple random sampling, Thiruvattar block was selected out of nine blocks in Kanyakumari district, then three PHCs under it were selected and finally, ten subcenters under these PHCs were selected. From the final ten subcenter populations, 25 persons were chosen from each cluster to get 250 subjects.

Inclusion criteria: Elderly people more than 60 years of age and who were permanent residents of Thiruvattar were included in the study.

Exclusion criteria: Debilitated or seriously ill elderly who could not give a coherent reply to questions.

Sample collection: Twenty-five subjects were chosen from each subcenter population. Those who were not willing for the study or were unavailable even after 2 visits were skipped and the next household with elderly in the family register of subcenter was included. Ethical clearance was obtained from Institutional.

Ethical Clearance Committee before starting the study. The subjects were interviewed with a pretested questionnaire by the principal investigator. Privacy was ensured and informed consent was 
Obtained before conducting the interview.

Data entry: Microsoft Office Excel 2007.

Data analysis: SPSS version 16

Statistical methods: Descriptive statistics, Chi square test, Fisher's exact test and binomial logistic regression were used for data analysis with a predetermined statistical significance level of $5 \%$.

\section{Results}

Socio demographic profile: The age distribution of the study group ranges from 60 to 90 years. Mean age of the study group was 70.12 years (95\% CI 69.3, 70.9). About 130 out of the total 250 study population were women comprising $52 \%$, while men formed $48 \%$ (120) of the population. Across the 250 elderly subjects, Hindus formed the majority at $56.8 \%$ (142), followed by Christians at 33.6\% (84) and Muslims at $9.6 \%(24)$.

Among the 250 elderly people, 60\% (150) of them were currently married (95\% CI 54, 66\%), while $36.8 \%$ (92) of them lost their spouses to death. One person was divorced and $1.2 \%$ (3) of them was separated from their spouses.

Another $1.6 \%$ (4) of them were never married. About $68 \%$ (170) of the elderly have completed their education up to high school level (95\% CI $62.2,73.8 \%$ ), while $14.4 \%$ (36) elderly were illiterate. $13.6 \%$ (34) of the elderly have a graduate degree. Of the 36 illiterate elderly, $66.7 \%$ were women. About one fourth of the elderly were engaged in skilled and unskilled occupations previously, through the main course of life or before retiring (25.6\% and $25.2 \%$, respectively).

About 34\% elderly were unemployed throughout life. However, currently around $70.8 \%$ elderly were unemployed. Among the elderly who were still working, majority were doing unskilled labour $(15.6 \%)$. Among the female elderly population, $63.8 \%$ women were unemployed previously while $69.2 \%$ were currently unemployed.

\section{Table-1: Background characteristics of study participants.}

\begin{tabular}{|c|c|c|c|}
\hline Characteristics & Male $(n=120) \mid$ & Female $(n=130)$ & Total $(\mathrm{N}=250)$ \\
\hline \multicolumn{4}{|l|}{ Marital status } \\
\hline \multirow{4}{*}{$\begin{array}{l}\text { Currently married } \\
\text { Widowed } \\
\text { Separated/divorced } \\
\text { Never married }\end{array}$} & $93(77.5)$ & $57(43.8)$ & $150(60)$ \\
\hline & $23(19.2)$ & $69(53)$ & $92(36.8)$ \\
\hline & $1(0.8)$ & $3(2.3)$ & $4(1.6)$ \\
\hline & $3(2.5)$ & $1(0.7)$ & $4(1.6)$ \\
\hline
\end{tabular}

\begin{tabular}{|c|c|c|c|}
\hline \multicolumn{4}{|l|}{ Type of family } \\
\hline \multirow{4}{*}{$\begin{array}{l}\text { Nuclear } \\
\text { Extended } \\
\text { Joint } \\
\text { Single member family }\end{array}$} & $61(50.8)$ & $42(32.3)$ & $103(41.2$ \\
\hline & $44(36.7)$ & $66(50.7)$ & $110(44)$ \\
\hline & $2(1.7)$ & $4(3)$ & $6(2.4)$ \\
\hline & $13(10.8)$ & 18(13.8) & $31(12.4)$ \\
\hline \multicolumn{4}{|l|}{ Educational status } \\
\hline \multirow{4}{*}{\begin{tabular}{|l} 
Illiterate \\
Primary school \\
High school \& Diploma \\
Graduate \& above
\end{tabular}} & $12(10)$ & $24(18.4)$ & $36(14.4)$ \\
\hline & 39 (32.5) & $54(41.5)$ & $93(37.2)$ \\
\hline & 45 (37.5) & $42(32.3)$ & $87(34.8)$ \\
\hline & $24(20)$ & $10(7.6)$ & $34(13.6)$ \\
\hline \multicolumn{4}{|l|}{ Previous occupation } \\
\hline \multirow{5}{*}{$\begin{array}{l}\text { Professional } \\
\text { Clerical } \\
\text { Skilled } \\
\text { Unskilled } \\
\text { Unemployed }\end{array}$} & $14(11.7)$ & $4(3)$ & $18(7.2)$ \\
\hline & $14(11.7)$ & $6(4.6)$ & $20(8)$ \\
\hline & $21(17.5)$ & $7(5.3)$ & $63(25.2)$ \\
\hline & $34(28.3)$ & $30(23)$ & $64(25.6)$ \\
\hline & $2(1.7)$ & $83(63.8)$ & $85(34)$ \\
\hline \multicolumn{4}{|l|}{ Current occupation } \\
\hline \multirow{6}{*}{$\begin{array}{l}\text { Semi Professional } \\
\text { Clerical } \\
\text { Skilled } \\
\text { Semi skilled } \\
\text { Unskilled } \\
\text { Unemployed }\end{array}$} & $5(4.2)$ & $1(0.7)$ & $6(2.4)$ \\
\hline & 0 & $4(3)$ & $4(1.6)$ \\
\hline & $1(0.8)$ & $5(3.8)$ & $6(2.4)$ \\
\hline & $6(5)$ & $13(10)$ & $19(7.6)$ \\
\hline & $22(18.3)$ & $17(13)$ & $39(15.6)$ \\
\hline & $5(4.2)$ & $90(69.2)$ & $177(70.8)$ \\
\hline \multicolumn{4}{|l|}{ Source of income } \\
\hline \multirow{5}{*}{$\begin{array}{l}\text { Pension } \\
\text { Remittance by children } \\
\text { Jobs } \\
\text { Other sources } \\
\text { No income }\end{array}$} & $33(27.5)$ & $37(28.4)$ & $70(28)$ \\
\hline & $25(20.8)$ & $42(32.3)$ & $67(26.8)$ \\
\hline & $54(45)$ & $8(6.1)$ & $62(24.8)$ \\
\hline & $5(4.2)$ & $1(0.7)$ & $6(2.4)$ \\
\hline & $3(2.5)$ & $42(32.3)$ & $45(18)$ \\
\hline \multicolumn{4}{|l|}{ Socio-economic status } \\
\hline \multirow{4}{*}{$\begin{array}{l}\text { Upper middle class Lower middle class } \\
\text { Upper lower class Lower class }\end{array}$} & $13(10.8)$ & $12(9.2)$ & $24(9.6)$ \\
\hline & $37(30.8)$ & $39(30)$ & $76(30.4)$ \\
\hline & $67(55.8)$ & $68(52.3)$ & $135(54)$ \\
\hline & $3(2.5)$ & $11(8.4)$ & $14(5.6)$ \\
\hline
\end{tabular}

*Percentages in parentheses

More than half of the elderly people belonged to upper lower SES (54\%) while 30.4\% elderly belonged to lower middle class. Only a small proportion of elderly belonged to Upper middle class and lower class at $9.6 \%$ and $5.6 \%$ respectively. Most of the elderly people lived in extended families (44\%). About a quarter of elderly each claimed pension, remittances from children and jobs as a source of income while $18 \%$ elderly had no income at all. The baseline characteristics of the study population are described in detail in Table 1.

Healthcare utilization among elderly: More than half of the elderly population interviewed, ie, 57.6\% (95\% CI $51.5,63.7 \%$ ) claimed to avoid going to or getting admitted in healthcare facilities in times of 
Need. That they would utilise healthcare facilities in case of need. The most commonly cited reasons for not utilising health facilities are the cost of hospital care $(27.6 \%)$ and that the elderly feel their illness is not important enough (26.4\%). The other reasons cited were that their children did not allow them to get admitted in hospitals, they do not believe in allopathic drugs, etc and account for $0.8 \%$ of responses. The reasons cited by the elderly are as listed below in Table 2 .

Table-2: Reasons affecting utilization of Healthcare Facilities (HCF) among elderly

\begin{tabular}{|l|l|l|}
\hline \multicolumn{1}{|c|}{ Reasons } & Frequency & Percent \\
\hline Cost of Hospital care & 69 & 27.6 \\
\hline Travel to HCF & 11 & 4.4 \\
\hline No bystanders & 25 & 10 \\
\hline Feel Illness not important & 66 & 26.4 \\
\hline Do not want to be a burden & 45 & 18 \\
\hline Other factors & 2 & 0.8 \\
\hline
\end{tabular}

*Multiple responses per subject

About $42 \%$ of the elderly population claimed they are on regular medication always (95\% CI 35.9, $48.1 \%$ ), while $38.4 \%$ elderly said they take regular medication 'sometimes' as opposed to $17.2 \%$ who 'rarely' take and $2.4 \%$ who 'never' take any regular medicines. Only less than half of the elderly $(46.8 \%)$ claimed compliance with regular medications.

The remaining $53.2 \%$ elderly ( $95 \%$ CI $47.1,59.3 \%$ ) cited multiple reasons, as listed below in Table 3, for not complying with medical treatment regimes. The most commonly cited reasons for avoiding medicines were that the elderly felt that their illness was not important enough $(25.4 \%)$ and the high cost of medicines $(21.8 \%)$.

Table-3: Reasons cited by elderly for not complying with medical treatment

\begin{tabular}{|l|l|l|}
\hline \multicolumn{1}{|c|}{ Factors } & Frequency & \multicolumn{1}{c|}{ Percent } \\
\hline Forget about medicines & 37 & 14.9 \\
\hline Feel Illness not important & 63 & 25.4 \\
\hline No time for medicines & 3 & 1.2 \\
\hline High cost & 54 & 21.8 \\
\hline Side effects & 7 & 2.8 \\
\hline Others & 2 & 0.8 \\
\hline
\end{tabular}

* Multiple responses per subject

The most common way of meeting the healthcare expenses among the elderly was through Out of Pocket expenditure (OOP) in the case of $75.6 \%$ of the elderly (95\% CI 70.3, 80.9\%).
Other ways of meeting medical expense included private health insurance $(4.4 \%)$, state insurance $(0.4 \%)$ or loans from others, as in $34.8 \%$ of the elderly. Almost all of the elderly subjects interviewed (96\%) did not have any health insurance policy or scheme in their name. Only $4 \%$ were enrolled in health insurance schemes.

Among the 87 elderly persons with debt, personal expenses were cited as the most common reason for debt in $57.5 \%$ elderly. This was followed by medical expenses in almost one third of elderly $(33.3 \%)$, and other reasons like loans taken for farming, businesses, etc in $9.2 \%$ of the elderly.

Factors associated with utilization of Healthcare Facilities (HCF): Being younger than 75 years of age, education above primary school, being married, being currently unemployed and belonging to an upper socioeconomic status were the factors found to be significantly associated with better utilization of Healthcare Facilities (HCF) among the elderly on bivariate analysis. Gender, occupation before retirement or family type did not have a statistically significant association with better healthcare utilization. The statistically significant factors are described in detail below in Table 4.

Table-4: Factors associated with HCF utilization among the elderly

\begin{tabular}{|c|c|c|c|c|c|}
\hline \multicolumn{2}{|c|}{ Variables } & \multirow{2}{*}{\begin{tabular}{|c|}
$\begin{array}{c}\text { Utilize HCF } \\
\text { N (\%) }\end{array}$ \\
$91(45.5)$ \\
\end{tabular}} & \multirow{2}{*}{\begin{tabular}{|c|}
$\begin{array}{c}\text { Avoid utilize } \\
\text { HCF N (\%) }\end{array}$ \\
$109(54.5)$
\end{tabular}} & \multirow{3}{*}{\begin{tabular}{|c|} 
P- \\
value \\
$.047 *$
\end{tabular}} & \multirow{2}{*}{$\begin{array}{c}\text { OR }[+95 \% \\
\text { CI }]\end{array}$} \\
\hline Age & $<75$ yrs & & & & \\
\hline & $>75 y r s$ & $15(30)$ & $35(70)$ & & \\
\hline \multirow[t]{2}{*}{ Education } & $\begin{array}{l}\text { Above } \\
\text { primary }\end{array}$ & $67(55.4)$ & $54(44.6)$ & \multirow[t]{2}{*}{$.000 *$} & \multirow[t]{2}{*}{$2.8(1.7,4.8$} \\
\hline & Primary & $39(30.2)$ & $90(69.8)$ & & \\
\hline \multirow{2}{*}{$\begin{array}{l}\text { Marital } \\
\text { status }\end{array}$} & Married & $75(50)$ & $75(50)$ & \multirow[t]{2}{*}{$.003 *$} & \multirow[t]{2}{*}{$2.2(1.3,3.8$} \\
\hline & Single & $31(31)$ & $69(69)$ & & \\
\hline \multirow{2}{*}{$\begin{array}{l}\text { Presently } \\
\text { employed }\end{array}$} & No & $82(42.6)$ & $94(53.4)$ & \multirow[t]{2}{*}{.039* } & \multirow{2}{*}{$\begin{array}{l}1.8(1.03 \\
3.2)\end{array}$} \\
\hline & Yes & $24(32.4)$ & $50(67.6)$ & & \\
\hline \multirow[t]{2}{*}{ SES } & Upper & $56(55.4)$ & $45(44.6)$ & \multirow[t]{2}{*}{$.001 *$} & \multirow[t]{2}{*}{$2.5(1.5,4.1)$} \\
\hline & Lower & $50(33.6)$ & $99(66.4)$ & & \\
\hline
\end{tabular}

$* \mathrm{P}<0.05$ is considered to be statistically significant

Binomial logistic regression models were built for proper utilization of HCF against the associated independent variables from bivariate analysis. The final regression model for factors with a statistically significant association with utilizing healthcare included education above primary school level $(p=0.02)$ and upper socioeconomic status $(p=0.01)$.

Factors like marital status, current unemployment and age less than 75 years were removed from 
Regression model as they were not statistically significant. The elderly belonging to upper SES were 2.2 times more likely to utilize healthcare than those belonging to lower SES (OR 2.2; 95\% CI 1.2, 4). Elderly people educated beyond primary school level were two times more likely to utilize healthcare properly than elderly educated up to primary level alone (OR 2; 95\% CI 1.1, 3.5).

\section{Discussion}

In the present study, $57.2 \%$ of elderly subjects belonged to the age group of $60-69$ years, 34\% were aged from 70 to 80 years and $8.8 \%$ were above 80 years of age. Goel et al. in Meerut found $47.2 \%, 37.8 \%$ and $15 \%$ of elderly in young elderly, old elderly and the oldest elderly groups, respectively [8].

Lena et al. had a higher proportion of elderly in the 60-69 age group (72.3\%) with a very small fraction of oldest elderly (2.8\%) in their study in Udupi [9].

Out of the 250 elderly subjects studied, $70.8 \%$ of the elderly were currently unemployed, which is higher than NSSO findings of $64 \%$ and other Government of India figures of $52.9 \%$ unemployment among rural elderly $[10,11]$. About $29.2 \%$ of the elderly in our study were working currently, of whom $54.1 \%$ were women and $45.9 \%$ were men.

The proportion of elderly who were unemployed for most part of their life in our study was $34 \%$ while $66 \%$ elderly had worked in some sort of employment for most part of their life. The ageing report found a similar percentage of $64.4 \%$ elderly who had ever worked at all in their life [5].

Regarding income source, $24.8 \%$ of the elderly in our study earned income through work while $28 \%$ received a pension and $18 \%$ had no income at all. Vedantam et al reported similar findings of $22 \%$ earning elderly and $29 \%$ receiving a pension in Kaniyambadi block, Tamil Nadu [12].

But in that study $49 \%$ subjects claimed to have no income. Remittances from children were not taken into account in that study, whereas in our study, $26.8 \%$ of elderly had claimed remittances as a source of income thus accounting for the discrepancy in numbers.

Extended family was the most common type of family in our study at $44 \%$ with nuclear families also predominant at $41.2 \%$. However, Sharma et al.
Found $89.5 \%$ of elderly belonging to joint families [13]. This may be due to the differences in the definition used for joint and extended families in our study.

As per our study, more than half of the elderly population (58\%) in rural areas of Kanyakumari district avoid utilization of healthcare facilities due to the high cost of healthcare $(27.6 \%)$ and because they perceive their illness to be trivial (26.4\%). Similar patterns of reasons for avoiding healthcare facilities were seen in other studies though healthcare utilization was much better among their elderly.

In a study by Sharma et al, $84 \%$ of the rural and urban elderly in Shimla were suffering from at least one medical problem and two thirds of the elderly (65.8\%) were seeking treatment for their problems [13]. This projects a higher utilization of healthcare facilities among the Shimla elderly but area of residence may be a potential confounding factor.

Elderly living in urban areas of Shimla were significantly more likely to access health services than the rural elderly, because they lived closer to these services. Among the reasons cited by Shimla elderly for not seeking treatment, most common reason reported was that 'morbidities were part of old age', followed by perceived distance to the healthcare facilities.

This is similar to the elderly in our study not utilizing healthcare because they feel their illness is not important.

Another study by Nipun et al in Bareilly, Uttar Pradesh also found a higher health seeking behaviour (65\%) among elderly [7]. Among the reasons cited by the elderly in Bareilly for not seeking treatment, the most common was affordability, followed by long waiting time and long distances.

In our study also, travel to healthcare facilities was cited as a reason for avoiding hospitals, though by fewer elderly. Health seeking behaviour of rural elderly in Mangalore was much better with $97.4 \%$ elderly seeking treatment for their health problems but even less aged people (72\%) visiting a health facility for checkups for their chronic conditions [14].

Among the factors influencing utilization of healthcare among elderly, those with education above primary school level in our study were two times more likely to utilize healthcare facilities than 
Elderly with education at or below primary level.

A similar finding was reported by Arokiasamy et al in 2010 where they found elderly who were high school graduates were four times as likely in Maharashtra and twice as likely in Uttar Pradesh to seek treatment when compared to illiterate elderly [15].

They also found that the older elderly (70 years and older) were significantly less likely to seek treatment when compared to the 60-69 category, while Muslims were more likely to seek treatment when compared to Hindus.

Also, elderly in SC/ST categories were 54\% less likely to seek treatment for existing conditions in Maharashtra when compared to other castes. Bhat et al identified age as the sole demographic factor influencing healthcare utilization [14].

However we did not find any significant association of healthcare utilization with age, gender or religion in our study.Agarwal et al reported a higher percentage of elderly men and single elderly (either widowed or separated) visiting the hospital for treatment when compared to elderly women or married elderly respectively in Bareilly [7].

They also got similar findings of elderly with education of high school level and beyond and belonging to upper class SES having better healthcare utilization than those with primary school education or lower SES, as in our study.

In our study, $34.8 \%$ of elderly had some amount of indebtedness which is higher than the Ageing report's findings of $10 \%$ of elderly households in debt, of which more households were rural than urban [5].

The fact that medical expenses were the reason for indebtedness in more than one third of our rural elderly subjects is alarming and suggests that high cost of healthcare has catastrophic impacts on households with aged people.

A reason for such catastrophic impacts may be that more than three fourths of our elderly subjects used out of pocket expenses to meet medical expenditure. This is similar to findings reported by Duggal in 2007 that $83 \%$ of healthcare expenses in India are private out-of-pocket (OOP) expenditures [16].

Dey et al reviewed the plight of elderly and concluded that in case of healthcare expenditure,
Those above 65 years spent on average about 1.5 times as much as those in the 60-64 year age category [17].

This shows the financial strain placed on households with elderly people increases with increasing age. Pal et al also noted that the probability of catastrophic OOP expenses in households with elderly is much higher when compared to households without elderly members [18].

The elderly have little recourse as insurance does not usually cover outpatient or drug purchases. Moreover, insurance plans only cover inpatient hospital expenses [19]. Most of the elderly in our study $(96 \%)$ were not covered under any state or private health insurance schemes.

The Ageing report also described only $2.3 \%$ elderly as having a health insurance policy, which is similar to our study finding of $4 \%$ of elderly being covered by health insurance [5].

However, even among the general population, health insurance coverage in India is very low. According to National Family Health Survey of 2004-2005, only $10 \%$ of households in India had at least one member of the family covered by any form of health insurance [20].

In the context of current trends of increasing dependence on investigations, unregulated cost of medicines and profit based healthcare provision, an exorbitant increase in healthcare expenditure is to be expected.

This may have the disastrous effect of putting affordable healthcare out of reach of elderly population. Improved coverage of health insurance schemes and better geriatric or palliative care facilities in rural areas are thus the need of the hour in improving cover and reach of healthcare facilities.

Involving community members or local self help groups in providing assistance to households with elderly people will reduce the burden on the family and improve healthcare utilization.

Organising mobile health camps, providing home delivery of regular medications and subsidising healthcare for the elderly will also improve medical compliance and treatment outcome in elderly with chronic diseases.

Special attention has to be paid to those elderly who belong to lower SES and those with only primary school education as they have been identified as being more likely to avoid healthcare utilization. 


\section{Conclusion}

Healthy ageing is the emerging challenge faced by health system and policy makers in India. Seeking healthcare services earlier will help to reduce morbidity and mortality among the elderly. The importance of healthcare in improving functionality has to be conveyed to the older persons and their family members who are the primary caregivers.

Affordable and universal healthcare suited to geriatric needs has to be made available to the rural elderly population. Health insurance coverage among the elderly was very poor. Financial protection through better insurance coverage and provision of good quality public health facilities will go a long way in improving healthcare utilization by the rural elderly.

\section{Study Implications}

This study has identified that more than half the rural elderly population avoid utilizing healthcare facilities in times of need claiming high cost and perception that illness is part of old age. Perception of disease as an age-related phenomenon has to be negated. Factors like lack of insurance coverage, low educational status and low income have been identified as factors having an impact on healthcare utilization. This evidence will guide policy makers in drafting public health reforms that will ensure equitable and affordable healthcare to the rural elderly population of India.

\section{Authors Contribution}

PRP was the principal investigator, wrote the manuscript and provided the data for the study while PJD helped with data tabulation and final proofreading.

\section{Reference}

01. Goman M, Zaidi A. Global Age Watch Index 2015- Index Report. London- Help Age International. 2015 November [cited on 2018 December 3].

Available from: [Article] [Crossref]

02. Fauci AS, Kasper DL, Longo DL, Hauser SL, Jameson JL et al. editors, Harrison's Principles of Internal Medicine. 19th edition, New DelhiMcGraw Hill. 2015; Vol-1, p-70-84.

[Crossref]
03. Kowal P, Kahn K, Nawi N, Naidoo N, Abdullah S, Bawah $A$, et al. Ageing and adult health status in eight lower income countries- The INDEPTH WHO-SAGE Collaboration, INDEPTH WHO- SAGE Supplement. Global Health Action. 2010 [accessed on 2016 February 17].

Available from: [Article] [Crossref]

04. Limwattananon $S$ et al. Catastrophic and poverty impacts of heath payments results from national household surveys in Thailand. Bull World Health Organ. 2007;Aug;85(8)600-606. doi: [Article] [Crossref]

05. United Nations Population Fund. Report on the status of Elderly in select states of India. New Delhi- UNFPA. 2012 November.

[Crossref]

06. Pandey A, Ploubidis GB, Clarke L, Dandona L. Trends in catastrophic health expenditure in India- 1993 to 2014. Bull World Health Organ. 2018; Jan 1;96 (1)18-28.

doi: [Article] [Crossref]

07. Nipun A, Prakash SV, Singh AK, Danish I. Healthcare services utilization by geriatric population in rural area of District Bareilly, India. Int J CurrMicrobiol App Sci. 2015; Vol 4 (Issue 5).

Available from: [Article] [Crossref]

08. Goel PK, Garg SK, Singh JV, Bhatnagar M, Chopra $H$, Bajpai SK. Unmet needs of the elderly in rural population of Meerut. Indian J Community Med. 2003; Vol 28 (4)165-166. [Crossref]

09. Lena A, Ashok K, Padma M, et al. Health and social problems of the elderly- a cross-sectional study in udupi taluk, karnataka. Indian J Community Med. 2009;Apr;34(2)131-4. doi: [Article] [Crossref]

10. Government of India. Morbidity, Health Care and Condition of the Aged- National Sample Survey 60 th round. New Delhi- Ministry of Statistics and Programme Implementation. 2006; March, Report No-507 (60/250/1).

[Crossref]

11. Government of India. Elderly in India. New Delhi- Ministry of Statistics and Programme Implementation. 2016, [cited on 2018 December 3].

Available from: [Article] [Crossref] 
12. Vedantam A, Subramanian V, Rao NV, et al. Malnutrition in free-living elderly in rural south India- prevalence and risk factors. Public Health Nutr. 2010;Sep;13(9)1328-32.

doi: [Article] [Crossref]

13. Sharma D, Mazta SR, Parashar A. Morbidity Pattern and Health-seeking Behavior of Aged Population residing in Shimla Hills of North India- A Cross-Sectional Study. J Family Med Prim Care. 2013 Apr;2(2)188-93. doi: [Article] [Crossref]

14. Bhat S, Kumar S. Study on health care seeking behaviour among elderly in rural area. Int J Med Sci Public Health. 2017;6[Cited on 2018 December 4].

Available from: [Article] [Article] [Crossref]

15. Agarwal B, Arokiasamy P. Morbidity prevalence and health care utilization among older adults in India. J of Applied Gerontol. 2010;29(2)155-79. [Crossref]

16. Duggal R. Healthcare in India- Changing the Financing Strategy. Social Policy and Administration. August 2007;41(4)386-394.

[Crossref]
17. Dey S, Nambiar D, Lakshmi JK, Sheikh K, Reddy $\mathrm{KS}$. Aging in Asia- Findings from New and Emerging Data Initiatives. National Academies Press. 2012.

[Crossref]

18. Pal R. Analysing Catastrophic OOP Health Expenditure in India- Concepts, Determinants and Policy Implications. Mumbai- Indira Gandhi Institute of Development Research. 2010, [Accessed in 2018 December]. Available from: [Article] [Article] [Crossref]

19. Shahrawat R, Rao KD. Insured yet vulnerableout-of-pocket payments and India's poor. Health Policy Plan. 2012;May;27(3)213-21. doi: [Article] [Crossref]

20. Indian Institute of Population Sciences. NFHS-3, National Family Health Survey, 2005-06. Mumbai- Indian Institute of Population Sciences. 2007.

Available: [Article] [Crossref] 